\title{
Policy problems and policy design
}

\section{Juan Camilo Rave Restrepo iD}

FLACSO - Ecuador

jcravefl@flacso.edu.ec

Libro: Peters, Guy (2018). Policy problems and policy design. Chelteham: Edward Elgar Publishing.

\section{Resumen}

Se trata de una reseña del libro: "Policy problems and Policy Design", escrito por Guy Peters y publicado por la editorial Edward Elgar en el año 2018. La obra reseñada nutre las discusiones actuales sobre marcos analíticos para el diseño de políticas. En este escrito se plantea que la novedad de la obra reside en dos aspectos. El primero es la reconciliación del diseño de políticas con las teorías generales y holísticas del diseño. La segunda, es la repolitización del proceso de diseño de politicas frente a visiones instrumentales y tecnocráticas del mismo.

Palabras clave: diseño de políticas, políticas públicas, vieja escuela, nueva escuela.

\section{Abstract}

This is a review of the publication "Policy problems and Policy Design" written by Guy Peters and published by the Edward Elgar Publishing. The reviewed work nurtures the current discussions about the policy design frameworks. In this paper it is stated that the novelty of the work resides in two aspects. The first is the reconciliation of policy design with a broader and holistic theroretical approach of design. The second is the repoliticization of the policy design process, in opposition with an instrumental and technocratic vision of designing.

Keywords: policy design, public policy, old school, new school.

Reseña: Recibida el 24 de marzo de 2019 y aprobada el 4 de febrero de 2020.

\section{Cómo citar este artículo:}

Rave, JC. (2020). [Revisión del libro Policy problems and policy design, de Guy Peters] Reflexión política 22(45), pp. 132-134. doi: https://doi.org/10.29375/01240781.3575

\section{Policy problems and policy designn}

De apariencia deformada, expulsado y reintegrado al Olimpo, hijo de Zeus y de Era. Se trata de Hefesto, el herrero divino de la mitología griega. En el preludio de "The Design Way”, Nelson y Stolerman (2003), elevan a Hefesto como el "diseñador arquetípico", ello, porque en su lectura del mito, el dios lisiado expande su talento creativo como compensación de su desbalance físico. En otras palabras, Hefesto diseña para sobrevivir. Desde este lugar se dibuja una narrativa del diseño que posiciona su naturaleza como posibilidad de transformación, creación, imaginación de lo que aún no existe y encuadramiento de la utopía.

El rasgo primordial de la nueva producción del profesor Peters (2018) reside en visibilizar la potencia del diseño como mecanismo transformador de la realidad social y política. Lo anterior, a través de una reflexión teórica que convoca a superar la miopía y observar el gran panorama ¿Qué significa ello? En la teoría y en la práctica se presentan propuestas simplificadas del diseño de políticas, que esterilizan su diálogo con otros marcos holísticos y transdisciplinares del diseño como práctica de pensamiento experimental (Buchanan, 1992). En su libro, Peters (2018) elabora una disquisición entre una versión "vieja” y "nueva” del diseño de políticas. Para ello, inicia dando un paso hacia atrás y explicita 
el contenido de la relación entre "diseño" y "política" como cursos de acción para la obtención de cambios en un escenario factual. En un trabajo previo, el autor ya había anotado que los "juicios de valor" (value judgments) y la "actividades de búsqueda de normas" (norm-seeking activities) representan los elementos comunes que facilitaban la interacción entre el diseño y las políticas (Peters, 2017).

$\mathrm{El}$ autor presenta críticamente una versión reducida del diseño de las políticas como proceso lineal e ingenieril inspirado en una lógica de producción de artefactos. Frente a ello, le atribuye los siguientes rasgos problemáticos: a. el encajamiento en problemas individuales de política, b. la interpretación de los problemas públicos de manera retrospectiva, c. la tendencia "solucionista" que orienta su proceso, d. la asunción de los subsistemas de política como tabulas rasas y e. el peso excesivo sobre su dimensión instrumental con la consecuente opacidad de otros elementos cruciales del diseño.

En contraposición, el nuevo diseño de políticas públicas como propuesta basilar del texto, está inspirado en una concepción más integral del diseño. Se trata de una óptica en la que se privilegia la "iteración" y la "interactividad" como sinergias del proceso creativo. Desde este lugar, el diseño puede ser "organizacional", "dialógico" y/o "sistémico"; así mismo, su significado, el modo de instrumentarlo y las expectativas planteadas, se pluralizan y expanden, en tanto se resiste a ser compactado en una solo canal de transformación de realidad.

En términos epistemológicos la estrategia del autor es nítida, refuta la ortodoxia de la versión reductiva del diseño de las políticas por vaciar de contenido al diseño, apela a discusiones estructurales sobre el diseño en general y el modo en que se produce conocimiento en su órbita temática y revitaliza el debate sobre diseño de políticas para afrontar la sustancia de los problemas públicos contemporáneos.

La posibilidad de aterrizar una propuesta de diseño colaborativo, imperfecto, abierto, dialógico e inacabado, como respuesta a las limitaciones de una concepción más mecanística, vertical y tecnocrática, es posible por la sintonía del autor con debates de primer orden, atinentes a la relación que se ha construido en la filosofía occidental entre ciencia, arte y práctica (Dewey, 1958). Por un lado, encontramos un relato neopositivista sustentado en la jerarquización de la ciencia y el arte, la especialización teóricometodológica a través de las fronteras epistemológicas entre las artes liberales y una visión de la producción del conocimiento afincada en el "encuadramiento de las ideas en un orden fijo y natural" (Buchanan, 1992). Por otro lado, se observa una propuesta de ruptura en la que el conocimiento se genera a través de un nuevo tipo de "arte", dirigido hacía la producción de cambios. En este escenario, la ciencia es un arte, el arte es una práctica y la tecnología es el acicate de su relación circular (Dewey, 1958).

Peters convoca en su texto a un desplazamiento de una "actitud decisional" (decision attitude) a una "actitud de diseño" en la formulación de políticas públicas (design attiude) (2018). La diferencia entre ambas radica en que la primera presenta una versión superficial del diseño, en la que su objeto se agota en la fabricación de una batería de posibles intervenciones para solucionar un problema público. Por su lado, la segunda implica pensar el diseño como una instancia de interacciones sucesivas, cuya lógica procesa los problemas públicos, reconociendo sus niveles de "complejidad", "incerteza" y "desacuerdo". Lo anterior, en términos del tipo de interrelación que proponen sus partes, el efecto de la contingencia y la contienda respecto a la definición de sus límites y contexturas.

El argumento de Peters está enraizado a la discusión en la filosofía de la tecnología que -tambiénpropone un movimiento de la interpretación de la tecnología como saber que estudia la producción y uso de artefactos, hacía una visión de aquella como arte de pensamiento experimental; desde esta línea, Buchanan (1992) introduce el diseño como un espacio de interconexiones que se expande a través de los circuitos sociales. En efecto, si se trabaja bajo una concepción de diseño asociada a prácticas de planeación, proyección, elaboración de hipótesis, etc., entonces es potable la idea según la cual el diseño está presente en la mayor parte de la construcción de la experiencia humana.

Por lo anterior, el lector de la obra encontrará una propuesta teórica que si bien se encuentra afincada en el terreno del análisis de las políticas públicas, consigue robustez analítica a partir de la irradiación teórica ejercida desde enfoques integrativos del diseño, que cruzan distintos saberes teóricos y múltiples prácticas investigativas y creativas (Ackoff 1971, 1967; Özbekhan, 1970; Nelson \& Stolerman 2003). Finalmente, la obra que se reseña se caracteriza por su lenguaje claro, preciso y conciso. El autor alterna el proceso escritural con premisas prescriptivas y premisas descriptivas, en ciertos momentos, le 
habla al analista académico de políticas, dotándolo de herramientas para investigar sus casos, mientras que en otros, crítica la práctica administrativa de gestión, elabora recomendaciones y señala rutas de acción para el policy-maker.

En otra publicación reciente del mismo autor con otros investigadores (Peters et al 2018) se planteó la "efectividad" como móvil central y orientador del diseño de política públicas, de acuerdo a los autores, dicha categoria puede entenderse en tres niveles de análisis, el primero tienen que ver con el espacio o ambiente que conduce a un diseño efectivo, el segundo está relacionado con la construcción de portafolios de instrumentos mixtos (policy tool bundles) para la obtención de objetivos de política, en otras palabras la generación de un "proceso" de diseño efectivo, el último, le concierne los modos y patrones de selección individual de herramientas de política.

En el texto que se reseña hay varios elementos que pueden generar un diálogo crítico entre ambas propuestas, en mi opinión, pueden plantearse las siguientes preguntas: ¿cómo la propuesta de nuevo diseño afronta la cuestión de la efectividad como valor orientador del proceso creativo?, ¿por qué el posicionamiento de la efectividad como modulador del diseño puede legitimar la concepción de la vieja escuela, que otorga un peso mayúsculo a la dimensión instrumental del diseño?, ¿cómo imbricar la noción de efectividad con valores de resorte democrático y humanístico?

\section{Referencias:}

Ackoff, R. L. (1967). Management misinformation systems. Management science, 14(4), B-147.

Ackoff, R. L. (1971). Towards a system of systems concepts. Management science, 17(11), 661-671.

Buchanan, R. (1992). Wicked problems in design thinking. Design issues, 8(2), 5-21.

Dewey, J. (1958). Experience and nature (Vol. 471). Courier Corporation.

Nelson, H. G., \& Stolterman, E. (2003). The design way: Intentional change in an unpredictable world: Foundations and fundamentals of design competence. Educational Technology.

Özbekhan, H. (1970). The predicament of mankind: A quest for structured responses to growing world- wide complexities and uncertainties. New York: Club of Rome.
Peters, B. G., Capano, G., Howlett, M., Mukherjee, I., Chou, M. H., \& Ravinet, P. (2018). Designing for policy effectiveness: Defining and understanding a concept. Elements in Public Policy. 